\title{
Knowledge, Attitude, and Practices regarding Leptospirosis among Visitors to a Recreational Forest in Malaysia
}

\author{
Nur Juliani Shafie, ${ }^{1 \star}$ Najma Syahmin Abdul Halim, ${ }^{1}$ Mohamed Nor Zalipah, ${ }^{1}$ Nur Amalin Zahirah Mohd Amin, ${ }^{1}$ \\ Sharifah Masit'ah Syed Esa, ${ }^{1}$ Shukor Md-Nor, ${ }^{2}$ Arnau Casanovas-Massana, ${ }^{3}$ Albert I. Ko, ${ }^{3,5}$ Fabiana Palma, ${ }^{4}$ \\ Fabio Neves Souza, ${ }^{4}$ and Federico Costa $^{3,4,5}$ \\ ${ }^{1}$ Faculty of Science and Marine Environment, Universiti Malaysia Terengganu, Terengganu, Malaysia; ${ }^{2}$ School of Environmental and Natural \\ Resource Sciences, Universiti Kebangsaan Malaysia, Bangi, Malaysia; ${ }^{3}$ Department of Epidemiology of Microbial Diseases, Yale School of Public \\ Health, New Haven, Connecticut; ${ }^{4}$ Institute of Collective Health, Federal University of Bahia, UFBA, Salvador, Brazil; ${ }^{5}$ Oswaldo Cruz Foundation, \\ Brazilian Ministry of Health, Salvador, Bahia, Brazil
}

\begin{abstract}
Leptospirosis is a zoonotic disease and a worldwide public health problem that affects mainly high-risk groups. Characterizing knowledge, attitude, and practice (KAP) among high-risk groups is important to develop appropriate prevention programs. Here, we performed a cross-sectional study among 300 visitors of a recreational forest in Malaysia to examine leptospirosis KAP and demographics. These variables were integrated to create knowledge and practice scores for each respondent. All respondents had heard about leptospirosis, and $87 \%$ of them correctly identified it as a disease. The majority of respondents had high knowledge (63\%), positive attitude, and good practice (68\%) toward prevention of the disease. However, there were gaps in knowledge, with $78 \%$ of the respondents indicating eating without washing hands as the major cause of leptospirosis transmission. Our final model identified that higher knowledge score was associated with higher practice score. Our results indicate that it is important to increase knowledge, especially on transmission routes of leptospirosis, among visitors in recreational areas. Moreover, more attention needs to be paid to promote good practice habits among visitors, targeting those at higher risk of being infected by leptospirosis to prevent potential outbreaks in the recreational areas.
\end{abstract}

\section{INTRODUCTION}

Leptospirosis is a globally distributed zoonotic disease with more than one million cases and 50,000 deaths annually. ${ }^{1}$ Leptospirosis shows a range of symptoms in humans such as high fever, headache, jaundice, renal failure, meningitis, hemorrhagic fever, abdominal pain, and muscle aches; however, most infections are subclinical. ${ }^{2}$ Leptospirosis is caused by pathogenic spirochetes from the genus Leptospira. Pathogenic Leptospira spp. infect and colonize the kidneys of almost all mammalian species ${ }^{3}$ and are excreted at high concentrations ${ }^{4,5}$ into the environment where they can survive for extended time. ${ }^{6}$ Small mammals, and specifically rodents, are chronic carriers of Leptospira that act as the major reservoir host in the transmission of leptospirosis. ${ }^{3}$ Infection occurs either through direct contact of broken skin, abrasion, or mucous membranes with urine or tissue of infected animal, or indirect contact with contaminated soil and water. ${ }^{7}$ Leptospirosis is highly prevalent in the Asia Pacific region, and specifically in Southeast Asia and Oceania. ${ }^{1,3}$ The estimated incidence of leptospirosis ranges from 0.1 to 1 for every 100,000 per year in temperate climates, but it can be as high as 10-100 per 100,000 in tropical regions, and more than 100 per 100,000 among high-risk groups during outbreaks. ${ }^{8}$ The high prevalence of leptospirosis in Southeast Asia has been related to flooding, recreational activities, occupational exposure, travel to endemic regions, poor sanitation, and waste disposal. ${ }^{3}$

Leptospirosis is endemic in Malaysia, and the first case was reported in $1925 .^{9}$ A total of 12,325 cases with 338 deaths were reported between 2004 and $2012 .{ }^{10}$ According to the Ministry of Health Malaysia, ${ }^{11}$ Terengganu was among the five states in Malaysia with the highest number of leptospirosis

* Address correspondence to Nur Juliani Shafie, Faculty of Science and Marine Environment, Universiti Malaysia Terengganu, 21030 Kuala Nerus, Terengganu, Malaysia. E-mail: nur.shafie@umt.edu.my cases $(\approx 8.00$ per 100,000 population), and recreational areas were categorized as one of the important hotspots of leptospirosis outbreaks. In Malaysia, most recreational areas are equipped with many infrastructures such as community halls, chalets, public toilets, and food stalls. ${ }^{12}$ However, poor sanitation and waste disposal make recreational areas favorable environments for the transmission of leptospirosis. The presence of pathogenic Leptospira has been previously reported in two recreational areas in Terengganu, Lata Tembakah Waterfall and Lata Belatan Waterfall, with 5\% (1/20 water and soil samples) and $10 \%$ (2/20 water and soil samples) positive samples, respectively. ${ }^{13}$ Several factors have been identified as contributing to the increasing number of outbreak, including water $\mathrm{pH}$, temperature, soil moisture, and the presence of wild animals which act as reservoirs. ${ }^{13,14}$ Rattus tiomanicus was found to be the dominant carrier with $88.1 \%$ prevalence $(37 / 42$ leptospiral isolates) for serovars Icterohaemorrhagiae, Canicola, Ballum, Pyrogenes, and Hebdomadis. ${ }^{15}$ Serovar hebdomadis was also reported as the dominant serovar in Terengganu. ${ }^{14}$

Despite the increasing incidence, leptospirosis is often neglected, and there is still a lack of awareness and basic knowledge on the disease, especially among high-risk groups. ${ }^{16}$ Understanding the knowledge of individual subjects and their attitudes with respect to risky behaviors is key to implementing better prevention practices. Similarly, it is also important to identify the sociodemographic characteristics that influence individual behaviors and their prevention practices of leptospirosis. ${ }^{17}$ Knowledge, attitude, and practice (KAP) studies on leptospirosis conducted in Malaysia have focused mainly on describing the KAP among urban and rural communities, ${ }^{18,19}$ residents in floodprone areas, ${ }^{20,21}$ town service workers, ${ }^{22}$ wet market workers, ${ }^{23}$ non-high-risk group, ${ }^{24}$ and university students. ${ }^{25}$ Yet, there are no KAP studies on leptospirosis conducted among visitors of recreational areas, which limits our ability to understand their level of awareness toward the prevention of leptospirosis. Here, we aimed to identify KAP related to leptospirosis among visitors of 
Lata Belatan, a recreational forest in Besut (Terengganu, Malaysia), and to determine the factors that influence leptospirosis prevention practices.

\section{MATERIALS AND METHODS}

Study area. This study was conducted in Lata Belatan, a recreational forest in Terengganu, Malaysia $\left(5^{\circ} 63^{\prime} 90^{\prime \prime} \mathrm{N}, 102^{\circ} 58^{\prime} 78^{\prime \prime} \mathrm{E}\right)$. This recreational forest is located at the base of Gunung Tebu in Besut, Terengganu (Figure 1). It consists of fast-flowing cascades and clear water that attracts visitors from Terengganu, other states in Malaysia, and foreigners. This recreational area is characterized by lowland riparian forest and low hill dipterocarp forest. ${ }^{26}$ There are also many facilities provided for the visitors such as food stalls, public toilets, camping sites, rest areas, and a prayer room.

Study design. We conducted a cross-sectional study among visitors of Lata Belatan Recreational Forest. A list of 345 respondents were selected randomly from a database from the Department of Forestry Terengganu $(N=13,043)$ using IBM SPSS Statistics for Windows version 21 (IBM Corp.,
Armonk, NY). The sample size was calculated based on $95 \%$ $\mathrm{Cl}, 5 \%$ margin of error, and $50 \%$ positive response rate. However, $13 \%(N=45)$ of nonresponse was detected because of failure to reach. Inclusion criteria were $>16$ years old, visited the recreational forest between January-June 2018, and agree to participate in the study. The questionnaire was prepared in Malay language (local dialect) because the local residents were predominantly Malay native speakers. All data and visitors' personal information were confidential. Parental consent letters were given for respondents younger than 18 years, and informed consent was also obtained from adult respondents before they participated in this study. Data collection was conducted using printed questionnaires from September 2018 until March 2019. The approval to conduct this study was obtained from Ethical Review Committee Board, Universiti Malaysia Terengganu (UMT/JKEPHT/2019/30).

Data collection. A questionnaire was developed using previous KAP studies on leptospirosis. ${ }^{27-29}$ The questionnaire consisted of 42 questions categorized into two sections: 1) sociodemographic characteristics (age, gender, educational

A

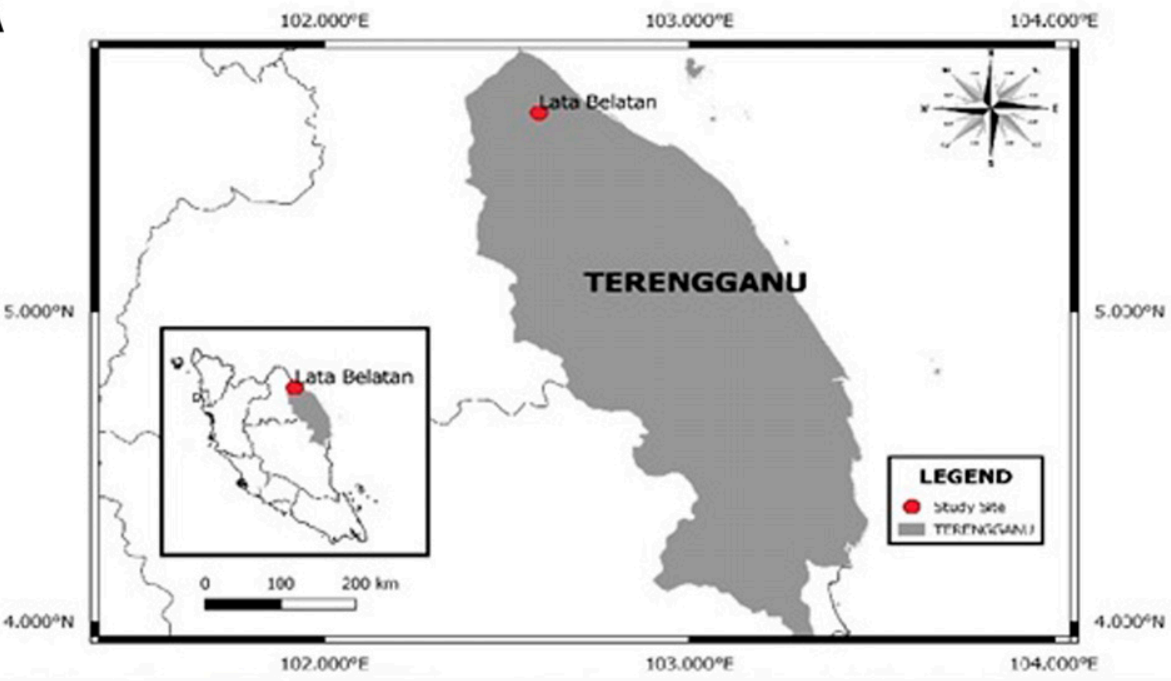

B

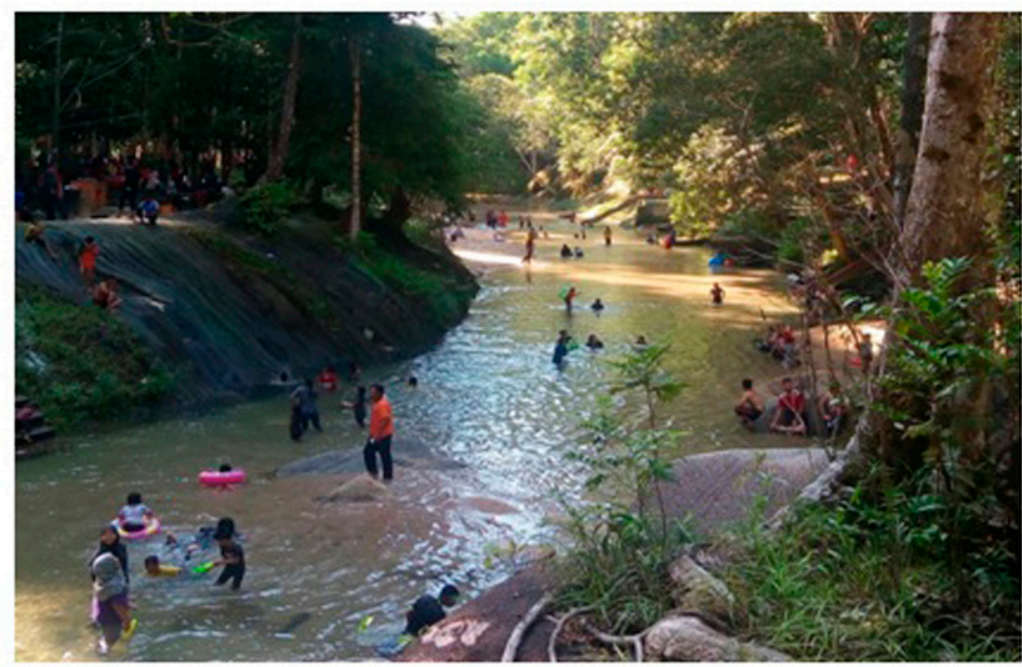

FIgURE 1. Lata Belatan Recreational Forest in Terengganu, Malaysia. (A) Location of the study site in Peninsular Malaysia and within the state of Terengganu; (B) visitors who are involved with recreational or water activities. This figure appears in color at www.ajtmh.org. 
level, occupation, and monthly income) and 2) KAP of leptospirosis. Knowledge related to leptospirosis was assessed by asking whether they had ever heard of "leptospirosis" or also known as "rat-urine disease" among local residents. The respondents were also asked questions about the 1) causative organism and disease transmission, 2) common symptoms, and 3) prevention practices regarding leptospirosis. Respondents were given three answer options including "true," "false," and "do not know." Each affirmative answer was given as one score, whereas negative answer and "do not know" were given as zero score. The attitude of the respondents toward leptospirosis was evaluated by asking questions on their reactions to statements about leptospirosis and other attitudinal issues based on a five-level Likert scale (one = strongly disagree, two = disagree, three $=$ not sure, four = agree, and five = strongly agree). ${ }^{30}$ Respondents who agreed or strongly agreed to the statements were considered to have a positive attitude, whereas respondents who were not sure, disagreed, or strongly disagreed were considered to have a negative attitude. The preventive practices were evaluated by asking them "yes or no" questions. Each "yes" answer was given one score, whereas "no" answer was given zero score. Scores for each individual were calculated and summed up to obtain the total score.

Data analysis. The data were coded, entered into Microsoft Excel 2013 (Microsoft Corp., Redmond, WA), and then imported to $R$ program for further analysis. ${ }^{31}$ Descriptive statistics including means and frequencies were calculated for knowledge and practice scores. Knowledge and practice scores were used as continuous variables. Sociodemographic characteristics and knowledge score were considered as independent variables and the practice score as the dependent variable. Generalized linear models (GLMs) with Poisson error family was used to determine the predictors and associations between dependent and independent variables. Subsequently, these variables were evaluated one by one in the univariate analyses, and determinants having a screening significance of $P<0.20$ were included in multivariate analyses. $^{32}$ Model simplification was carried, and we used the dredge 0 function of the "MuMIn" package. ${ }^{33}$ This function performs a set of models and valid combinations between the fixed variables of the multiple model, with all possible models ranked by the value of Akaike's information criterion (AIC). This process was continued by removing the least significant terms from the model until the minimum adequate model was achieved. When comparing two models, the smaller AIC was accepted as indicating the better fit. ${ }^{34}$ All $P$-values were considered statistically significant at $P<0.05$.

\section{RESULTS}

Sociodemographics. Of 300 respondents, there was an equal number of men and women $(49.3 \%$ and $50.7 \%$, respectively). Most respondents were aged between 21 and 30 years $(47.0 \%)$, and more than half of the respondents had completed tertiary education $(70.3 \%)$ (Table 1$)$. The main occupations were students (48.7\%) and private sector workers (22.6\%). The majority of participants did not have a monthly income (52.3\%), and the mean household income was Ringgit Malaysia 1,279 per month ( $\approx$ United States Dollar 303 ). This was expected considering most of respondents lived close to the recreational forest, where this study was conducted, which consists of low-income residential communities.
TABLE 1

Sociodemographic characteristics of the respondents $(N=300)$

\begin{tabular}{llrr}
\hline \multicolumn{1}{c}{ Category } & Profile of respondents & Number & Percentage \\
\hline Gender & Male & 148 & 49.3 \\
Age-group (years) & Female & 152 & 50.7 \\
& $16-20$ & 89 & 29.7 \\
& $21-30$ & 141 & 47.0 \\
& $31-40$ & 44 & 14.7 \\
Education & $>41$ & 26 & 8.7 \\
& Primary school & 0 & 0.0 \\
& Secondary school & 85 & 28.3 \\
& Tertiary education & 211 & 70.3 \\
Occupation & No formal education & 4 & 1.3 \\
& Student & 146 & 48.7 \\
& Private sector & 68 & 22.6 \\
& Government sector & 51 & 17.0 \\
& Housewife & 19 & 6.3 \\
& Unemployed & 11 & 3.7 \\
& Retired & 5 & 1.7 \\
Household income & RM 500 & 8 & 2.7 \\
& RM 500-RM 1499 & 38 & 12.7 \\
& RM 1500-RM 2499 & 39 & 13.0 \\
& RM 2500-RM 3499 & 17 & 5.7 \\
& RM 3500-RM 4999 & 20 & 6.7 \\
& > RM 5000 & 21 & 7.0 \\
& No income & 157 & 52.3 \\
\hline
\end{tabular}

Knowledge. All respondents had heard about leptospirosis, and $87.0 \%$ of them identified leptospirosis as a disease (Table 2). When asked about the causative agent of leptospirosis, $57.3 \%$ of respondents answered bacteria and $22.0 \%$ of respondents thought that parasites or worms were the causal organisms. Regarding the transmission of leptospirosis to humans, $78.0 \%$ answered eating without washing hands as the main risk factor. Only $47.3 \%$ of respondents knew contact with contaminated water and soil is one of the main factors of transmission. With regard to symptoms of leptospirosis, most of the respondents were aware of high fever (73.0\%), headache (72.0\%), and jaundice (51.0\%). The analysis of the knowledge score showed that of a maximum of 20 points, the mean score of the respondents was $11.1 \pm$ SD 5.1 (range: 0-19). A total of 189 respondents $(63.0 \%)$ were ranked above the mean score, indicating high knowledge among respondents.

When asked about prevention, $74.0 \%$ of respondents reported that the disease could be detected by blood tests and could be treated early (71.3\%). However, $22.0 \%$ of respondents thought that the disease could be prevented by taking a bath after water activities. In addition, 222 (74.0\%) respondents agreed that leptospirosis could cause death. The main source of information on leptospirosis was media (82.7\%), followed by community associations $(76.7 \%)$ and healthcare providers (41.7\%).

Attitude and prevention practices. In all the five statements used to measure attitude, high percentage of respondents had positive attitudes toward prevention and control of leptospirosis (Table 3). The majority of respondents believed that leptospirosis is a serious disease (87.7\%). They also had positive attitudes on the statement, "I must know about leptospirosis" (85.3\%) and "I should make sure that the recreational area is clean" (78.0\%). However, only $59.7 \%$ of respondents had positive attitude on the statement, "I believe that leptospirosis has a cure." A total of 204 respondents (68\%) scored above the mean score (3.0 \pm SD 1.5, range: 0-6), which indicates good practices against leptospirosis among 
TABLE 2

Proportion of respondents with affirmative answers for knowledge on leptospirosis $(N=300)$

\begin{tabular}{|c|c|c|}
\hline Knowledge regarding leptospirosis & Number & Percentage \\
\hline \multicolumn{3}{|l|}{ Leptospirosis } \\
\hline Leptospirosis is a disease & 261 & 87.0 \\
\hline $\begin{array}{l}\text { Bacteria are the causative agent of } \\
\text { leptospirosis }\end{array}$ & 172 & 57.3 \\
\hline $\begin{array}{l}\text { Viruses are the causative agent of } \\
\text { leptospirosis }\end{array}$ & 165 & 55.0 \\
\hline $\begin{array}{l}\text { Parasites or worms are the causative } \\
\text { agent of leptospirosis }\end{array}$ & 66 & 22.0 \\
\hline \multicolumn{3}{|l|}{ Transmission } \\
\hline $\begin{array}{l}\text { Eating without washing hands is a risk } \\
\text { to get leptospirosis }\end{array}$ & 234 & 78.0 \\
\hline $\begin{array}{l}\text { Leptospirosis is transmitted through rat } \\
\text { urine }\end{array}$ & 221 & 73.7 \\
\hline $\begin{array}{l}\text { Walking without shoes is a risk to get } \\
\text { leptospirosis }\end{array}$ & 204 & 68.0 \\
\hline $\begin{array}{l}\text { Leptospirosis can be transmitted } \\
\text { through cut skin wounds }\end{array}$ & 176 & 58.7 \\
\hline $\begin{array}{l}\text { Water activities are risky for } \\
\text { leptospirosis infection }\end{array}$ & 165 & 55.0 \\
\hline $\begin{array}{l}\text { Contaminated food is a risk for } \\
\text { leptospirosis infection }\end{array}$ & 145 & 48.3 \\
\hline $\begin{array}{l}\text { Leptospirosis can be transmitted } \\
\text { through contaminated water and soil }\end{array}$ & 142 & 47.3 \\
\hline \multicolumn{3}{|l|}{ Symptoms } \\
\hline Leptospirosis will cause high fever & 219 & 73.0 \\
\hline $\begin{array}{l}\text { Infected individuals will develop } \\
\text { headache }\end{array}$ & 216 & 72.0 \\
\hline Leptospirosis will cause jaundice & 153 & 51.0 \\
\hline Leptospirosis will cause liver damage & 120 & 40.0 \\
\hline \multicolumn{3}{|l|}{ Treatment and prevention } \\
\hline $\begin{array}{l}\text { The disease can be detected by a blood } \\
\text { test }\end{array}$ & 222 & 74.0 \\
\hline This disease can be treated early & 214 & 71.3 \\
\hline $\begin{array}{l}\text { The disease can be prevented by } \\
\text { maintaining cleanliness of } \\
\text { recreational area }\end{array}$ & 190 & 63.3 \\
\hline $\begin{array}{l}\text { The disease can be prevented by taking } \\
\text { a bath after water activities }\end{array}$ & 66 & 22.0 \\
\hline Leptospirosis can cause death & 222 & 74.0 \\
\hline \multicolumn{3}{|l|}{ Source of knowledge } \\
\hline $\begin{array}{l}\text { Media (newspaper, television, radio, } \\
\text { Internet) }\end{array}$ & 248 & 82.7 \\
\hline $\begin{array}{l}\text { Community associations (family, } \\
\text { friends, neighbor) }\end{array}$ & 230 & 76.7 \\
\hline Health care & 125 & 41.7 \\
\hline School & 78 & 26.0 \\
\hline Work & 44 & 14.7 \\
\hline
\end{tabular}

respondents. When asked about prevention practices, $90.3 \%$ of them maintained the cleanliness of the recreational area and $89.3 \%$ of respondents said that they always drank clean water supplies. However, only 171 (57.0\%) and 154 (51.3\%) of respondents mentioned wearing shoes in the recreational area and avoiding water activities, respectively, as prevention practices toward leptospirosis.

Regarding association of the respondent's sociodemographic characteristics with practice score, the univariate multiple Poisson regression (GLM) analysis (Table 4) showed that knowledge was significantly associated with practice against leptospirosis, females were more likely to have higher practice score than males (Odds ratio $[O R]=1.1 ; 95 \%$ confidence interval $[\mathrm{Cl}]=1.0-1.2$ ), and respondents $>30$ years old have higher practice score than respondents $<30$ years old $(\mathrm{OR}=1.1 ; 95 \% \mathrm{Cl}=1.0-1.2)$. In the final adjusted model, only knowledge score was associated with the practice against leptospirosis score $(\mathrm{aOR}=1.0 ; 95 \% \mathrm{Cl}=1.00-1.01)$. No significant differences were observed between practice score and other sociodemographic characteristics.

\section{DISCUSSION}

In this study, we performed a cross-sectional evaluation of the KAP related to leptospirosis among visitors of Lata Belatan, a recreational forest in Besut (Terengganu, Malaysia), and to determine the factors that influence leptospirosis prevention practices. Our results showed that all respondents had heard about leptospirosis, and $87.0 \%$ of them identified leptospirosis as a disease. The majority of respondents had high knowledge (63\%) and good practices $(68 \%)$ regarding leptospirosis based on their overall scores. However, a large proportion of respondents had a poor understanding on the transmission factors of the disease, especially on the role of contaminated water and soil in the transmission of Leptospira. Moreover, higher knowledge score was significantly associated with higher leptospirosis prevention practices.

All of the respondents had heard of leptospirosis, and $87.0 \%$ of them identified it as a disease, with an overall knowledge score of $63 \%$. The majority of the respondents had heard about leptospirosis from media (82.7\%) and also community associations $(76.7 \%)$ that involved knowledge sharing among families, friends, and neighbors. These findings are in agreement with previous studies that have shown that mass media are the main source of knowledge about leptospirosis. ${ }^{18,19,22,24}$ Media can be an effective channel to deliver messages to the public in a fastest way because faceto-face communications often require costly human resources. ${ }^{35}$ Public health social media campaigns are viewed as powerful tools to enhance health behaviors, attitudes, and awareness at a population level. ${ }^{36}$ However, the relevance of media and community associations need to be taken into account as not all information and knowledge received from the Internet and social networks are accurate and reliable.

Regarding transmission of leptospirosis, less than $50 \%$ of the respondents knew that contaminated water and soil are relevant risk factors for leptospirosis infection. Moreover, $22.0 \%$ of respondents thought that the disease could be prevented by rinsing their body after bathing in the waterfall. These findings are consistent with a previous study that found there is a gap in the knowledge regarding leptospirosis, especially on transmission routes and prevention measures. ${ }^{19}$ In our study, most of the respondents had misconceptions regarding leptospirosis because of the use of the layman term "rat-urine disease," which focuses only on rodents. However, human infection can occur from exposure to infected urine from a wide variety of non-rodent animals including bats, ruminants, carnivores, primates, wild boars, deers, and dogs. ${ }^{37-39}$ Leptospirosis can be prevented by avoiding direct or indirect contact with infected animals or possible contaminated water and soil, wearing protective clothing and shoes, maintaining personal hygiene, protecting any wounds or scars with medical plaster, and drinking clean water. ${ }^{8}$ Therefore, to improve prevention measures in recreational areas, it is important to provide this correct information and increase visitors' health education on leptospirosis.

Overall, most of the respondents had positive attitudes toward prevention and control of leptospirosis. Most of them strongly agreed and believe that leptospirosis is a serious disease and they must know about it. Leptospirosis 
TABLE 3

Proportion of respondents with positive answers for attitude and prevention practices related to leptospirosis $(N=300)$

\begin{tabular}{lcc}
\hline \multicolumn{1}{c}{ Item } & Number & Percentage \\
\hline Attitude & & \\
I believe leptospirosis is a serious disease & 263 & 87.7 \\
I must know about leptospirosis & 256 & 85.3 \\
I should make sure that recreational & 234 & 78.0 \\
area is clean & & \\
It is important to control rat population & 226 & 75.3 \\
I believe that leptospirosis has a cure & 179 & 59.7 \\
Practices & & \\
Maintain cleanliness of the recreational area & 271 & 90.3 \\
Drink clean water supply & 268 & 89.3 \\
Wash hands with soap and water & 241 & 80.3 \\
Scrutinize any broken wounds and scars & 209 & 69.7 \\
Wear shoes in the recreational area & 171 & 57.0 \\
Avoid water activities & 154 & 51.3 \\
\hline
\end{tabular}

was reported to be a silent killer disease as the infected person will be asymptomatic or experience mild symptoms that can be misinterpreted as a typical flu-like illness until it becomes fatal. ${ }^{40}$ It is important for them to know that leptospirosis is an acute disease, in order for them to understand the consequences of this disease. Most of the respondents strongly agreed that they will make sure the recreational area is clean. Even though this attitude might not be directly related to leptospirosis, it is still an important precautionary measure because poor hygiene will increase the population of Leptospira reservoirs and create favorable environments for its transmission. The high percentage of positive responses might be due to the phrasing of the questions for the attitudes. However, to minimize bias in this section, respondents were provided with equally balanced answer scales between positive and negative options. The respondents were given five-level answer scales: strongly disagree, disagree, not sure, agree, and strongly agree.

Our final model identified that respondents with higher knowledge score showed higher practice score than those with lower knowledge score. Our result is consistent with previous studies in the Philippines ${ }^{29}$ and Argentina ${ }^{41}$ that showed higher knowledge score on leptospirosis may influence a higher adoption of preventive practices, but no other studies have identified this association. Our finding suggests that increasing knowledge on leptospirosis is important to promote positive preventive practices in the community. According to the theoretical constructs in the
Health Belief Model (HBM), perceived severity and perceived susceptibility to a disease depend on individual knowledge about the disease. ${ }^{42}$ The HBM suggests that higher perceived severity and perceived susceptibility (perceived threat) lead to higher likelihood of positive behavior toward the disease. Increasing knowledge on leptospirosis among visitors may promote more concern about this disease, which in turns may affect leptospirosis prevention practices. Leptospirosis information through signage in the recreational area could help to convey important information about leptospirosis to the visitors. It was found that interpretive signage has successfully increased knowledge, awareness, and positive behavior among visitors at Penang National Park, Malaysia, on conservation aspects. ${ }^{43}$ In addition, the development and implementation of gamification is a promising and interactive approach to increase knowledge on health information by involving the participants in various activities. ${ }^{44-46}$ Gamification modules such as role play, puzzles, goal-oriented activities, and social media engagement have been applied successfully to increase knowledge among university students in Malaysia regarding leptospirosis. ${ }^{46}$

There were no associations between demographic factors (gender and age) with leptospirosis prevention practices. However, our univariate results identified that males and younger respondents were more likely to have lower practice scores against leptospirosis. Majority of the visitors in the recreational forest in this study were aged between 21 and 30 years. Previous studies in Malaysia showed that most of the positive cases on leptospirosis were reported to occur among males and those aged between 20 and 29 years as they are usually more involved with riskier occupational and outdoor activities. ${ }^{10,47,48}$ This tendency could be due to the frequent outdoor recreational activities among those groups without knowing or acknowledging the risk factors of leptospirosis. ${ }^{49}$ Thus, it is crucial to increase the knowledge and awareness among male and younger visitors in recreational areas. In addition, more comprehensive efforts should be established to educate these groups to change their behavior and to avoid infection of this disease.

This study has limitations. First, the respondents were not asked why they did or did not take precautionary measures. This question needs to be included to determine in details the reasons for respondents' responses. Second, this study was conducted in only one recreational area in Malaysia which may

TABLE 4

Multiple poisson regression (Generalized linear model [GLM]) analysis of the association between socio-demographic characteristics, knowledge score, and preventive practice score against leptospirosis $(N=300)$

\begin{tabular}{|c|c|c|c|c|}
\hline Variables & Categories & Odds ratio $(95 \% \mathrm{Cl})$ & Adjusted odds ratio $(95 \% \mathrm{Cl})$ & $P$-value \\
\hline \multirow[t]{2}{*}{ Gender } & Female & $1.08(0.98-1.20)$ & - & - \\
\hline & Male & 1 & 1 & _- \\
\hline \multirow{2}{*}{ Education } & Has formal education & $1.05(0.69-1.72)$ & - & - \\
\hline & No formal education & 1 & 1 & - \\
\hline \multirow[t]{2}{*}{ Age (years) } & $>30$ & $1.09(0.97-1.23)$ & - & - \\
\hline & $<30$ & 1 & 1 & - \\
\hline \multirow[t]{2}{*}{ Occupation } & Employed & $0.98(0.88-1.08)$ & - & - \\
\hline & Unemployed & 1 & 1 & - \\
\hline \multirow[t]{2}{*}{ Income } & No monthly income & $1.14(0.63-2.08)$ & - & - \\
\hline & Has monthly income & 1 & 1 & - \\
\hline Knowledge score & & $1.01(1.00-1.02)$ & $1.01(1.00-1.01)$ & 0.018 \\
\hline
\end{tabular}

The bold values show that female was more likely to have higher practice score than male, respondents $>30$ years old have higher practice score than respondents $<30$ years old and knowledge was significantly $(P<0.05)$ associated with practice. 
affect the generalizability of our findings. However, we believe that our initial findings provide reliable information on the level of KAP among individual on the specific setting of recreational areas.

In conclusion, this study demonstrated that most of the respondents had high knowledge, positive attitudes, and good practices toward prevention of leptospirosis. However, high percentage of them still had limited knowledge on its route of transmission and prevention measures. Our results suggest that appropriate education programs targeting the high-risk groups should be conducted to deliver and increase their knowledge on leptospirosis. Male and young respondents who perform recreational and outdoor activities were also found to have higher risk of being infected by leptospirosis in this area. The number of cases and deaths will continue to increase if there are no efficient measures taken to mitigate this situation. Public health workers, researchers, and policy-makers should improve prevention measures and treatments for this disease. Because community involvement is a key in public health, local communities themselves should also be involved in these approaches to reduce the burden of leptospirosis.

Received April 17, 2020. Accepted for publication December 6, 2020.

Published online January 18, 2021.

Acknowledgments: We thank Forestry Department of Peninsular Malaysia and Forestry Department of Terengganu for the approval and support to conduct this study. We also thank the visitors of Lata Belatan Recreational Forest, Terengganu, for participating in the study.

Financial support: The work presented in this study is funded by the Ministry of Higher Education, Malaysia, through UKM-UMT collaboration research grant (Vot 53138; 53269), the University of Putra Malaysia via Long-Term Research Grant Scheme (LRGS Phase 2/ 2014, UPM/700-2/7/LRGS/55264000), as well as the University of Malaya Research University Grant (RU005-2017), the Welcome Trust (102330/Z/13/Z and 218987/Z/19/Z), and the Brazilian National Council for Scientific and Technological Development (CNPq).

Authors' addressses: Nur Juliani Shafie, Najma Syahmin Abdul Halim, Mohamed Nor Zalipah, Nur Amalin Zahirah Mohd Amin, and Sharifah Masit'ah Syed Esa, Faculty of Science and Marine Environment, Universiti Malaysia Terengganu, Terengganu, Malaysia, E-mails: nur.shafie@umt.edu.my, najmasyahmin@gmail.com, zalipah@ umt.edu.my, zahirahnuramalin@gmail.com, and masitah97cetah@ gmail.com. Shukor Md-Nor, School of Environmental and Natural Resource Sciences, Universiti Kebangsaan Malaysia, Bangi, Malaysia, E-mail: shukor@ukm.edu.my. Arnau Casanovas-Massana and Albert I. Ko, Yale School of Public Health, New Haven, CT, E-mails: arnau.casanovas@yale.edu and albert.ko@yale.edu. Fabiana Palma, Fabio Neves Souza, and Federico Costa, Institute of Collective Health, Federal University of Bahia, UFBA, Salvador, Brazil, E-mails: fabiana.palma@yahoo.com.br, fabionevesouza@gmail.com, and fcosta2001@gmail.com.

This is an open-access article distributed under the terms of the Creative Commons Attribution (CC-BY) License, which permits unrestricted use, distribution, and reproduction in any medium, provided the original author and source are credited.

\section{REFERENCES}

1. Costa F, Hagan JE, Calcagno J, Kane M, Torgerson P, MartinezSilveira MS, Stein C, Abela-Ridder B, Ko Al, 2015. Global morbidity and mortality of leptospirosis: a systematic review. PLoS Negl Trop Dis 9: e0003898.

2. Bharti AR et al., 2003. Leptospirosis: a zoonotic disease of global importance. Lancet Infect Dis 3: 757-771.

3. Victoriano AFB et al., 2009. Leptospirosis in the Asia Pacific region. BMC Infect Dis 9: 147.
4. Costa F, WunderEA, De Oliveira D, Bisht V, Rodrigues G, Reis MG, Ko Al, Begon M, Childs JE, 2015. Patterns in Leptospira shedding in Norway Rats (Rattus norvegicus) from Brazilian slum communities at high risk of disease transmission. PLoS Negl Trop Dis 9: e0003819.

5. Barragan V et al., 2016. High Leptospira diversity in animals and humans complicates the search for common reservoirs of human disease in rural Ecuador. PLoS Negl Trop Dis 10: e0004990.

6. Casanovas-Massana A, Pedra GG, Wunder EA, Diggle PJ, Begon $\mathrm{M}, \mathrm{Ko}$ Al, 2018. Quantification of Leptospira interrogans survival in soil and water microcosms. Appl Environ Microbiol 84: e00507.

7. Ko Al, Goarant C, Picardeau M, 2009. Leptospira: the dawn of the molecular genetics era for an emerging zoonotic pathogen. Nat Rev Microbiol 7: 736-747.

8. WHO, 2007. Leptospirosis. Geneva, Switzerland: World Health Organization. Available at: http://apps.searo.who.int/PDS DOCS/B2147.pdf. Accessed April 2, 2019.

9. El Jalii IM, Bahaman AR, 2004. A review of human leptospirosis in Malaysia. J Trop Biomed 21: 113-119.

10. Benacer D, Thong KL, Min NC, Verasahib KB, Galloway RL, Hartskeerl RA, Souris M, Zain SNM, 2016. Epidemiology of human leptospirosis in Malaysia, 2004-2012. Acta Trop 157: 162-168.

11. $\mathrm{MOH}, 2015$. Epidemiology and Current Situation of Leptospirosis in Malaysia. Available at: http://moh.gov.my. Accessed April 2, 2019.

12. Adriansyah D, Busu I, Eva H, Muqtada M, 2015. Geoheritage as the basis of geotourism development: a case study in Jeli district, Kelantan, Malaysia. Geoj Tour Geosites 15: 25-43.

13. Ridzlan FR, Bahaman AR, Khairani-Bejo S, Mutalib AR, 2010. Detection of pathogenic Leptospira from selected environment in Kelantan and Terengganu, Malaysia. Trop Biomed 27: 632-638.

14. Ismail $S$ et al., 2014. A study on the presence of pathogenic Leptospira spp. in environmental water samples obtained from selected recreational areas in Terengganu, Malaysia. Res $J$ Pharm Tech 7: 1153-1157.

15. Mohamed-Hassan SN, Bahaman AR, Mutalib AR, Khairani-Bejo $S, 2012$. Prevalence of pathogenic leptospires in rats from selected locations in Peninsular Malaysia. Res $J$ Anim Sci 6: 12-25.

16. Schneider MC, Jancloes $M$, Buss DF, Aldighieri S, Bertherat $E$, Najera P, Galan DI, Durski K, Espinal MA, 2013. Leptospirosis: a silent epidemic disease. Int $J$ Environ Res Public Health 10: 7229-7234.

17. Azimullah AZ, Aziah BD, Fauziah BD, 2016. The rise of leptospirosis in Kelantan 2014: characteristics, geographical pattern and associated factors. Int J Public Health Clin Sci 3: 52-62.

18. Nozmi $\mathrm{N}$ et al., 2018. Low levels of knowledge, attitudes and preventive practices on leptospirosis among a rural community in Hulu Langat District, Selangor, Malaysia. Int J Environ Res Public Health 15: 693.

19. Sukeri S, Idris Z, Zahiruddin WM, Shafei MN, Idris N, Hamat RA, Jamaluddin TZT, Osman M, Wahab ZA, Daud A, 2018. A qualitative exploration of the misconceptions, knowledge gaps and constructs of leptospirosis among rural and urban communities in Malaysia. PLoS One 13: e0200871.

20. Edre MA, Hayati KS, Salmiah MS, Sharifah Norkhadijah SI, 2015. A case control study on factors associated with leptospirosis infection among residents in flood-prone area, Kuantan: a geographical information system-based approach. Int J Public Health Clin Sci 2: 151-163.

21. Edre MA, Hayati KS, Salmiah MS, Sharifah Norkhadijah SN, 2018. Determinants of leptospirosis preventive practices among the community in a flood-prone residential area in Kuantan, Malaysia. Mal J Med Health Sci 14: 27-33.

22. Azfar ZM, Nazri SM, Rusli AM, Maizurah O, Zahiruddin WM, Azwany YN, Nabilah I, Asma HS, Aziah BD, 2018. Knowledge, attitude and practice about leptospirosis prevention among town service workers in northeastern Malaysia: a cross sectional study. J Prev Med Hyg 59: e92-e98.

23. Rahman $M$ et al., 2018. Leptospirosis health intervention module effect on knowledge, attitude, belief, and practice among wet 
market workers in northeastern Malaysia: an Intervention Study. Int J Environ Res Public Health 15: 1396.

24. Sakinah SNS, Suhailah S, Jamaluddin TZMT, Norbaya SM, Malina O, 2015. Seroprevalence of leptospiral antibodies and knowledge, attitude and practices of leptospirosis to non-high risk group in Selangor. Int J Public Health Clin Sci 2: 92-104.

25. Bakar SMA, Rahman HA, 2015. Knowledge, attitude and practice on leptospirosis among undergraduate students in University Putra Malaysia. Mal J Med Health Sci 14: 104-111.

26. Sumarli AX, Grismer LL, Anuar S, Muin MA, Quah ES, 2015. First report on the amphibians and reptiles of a remote mountain, Gunung Tebu in northeastern Peninsular Malaysia. Check List 11: 1679.

27. Rahim MS, Aziah B, Nazri S, Azwany $Y$, Habsah H, Zahiruddin WM, Zahila I, Rusli MA, 2012. Town service workers' knowledge, attitude and practice towards leptospirosis. Brunei Darussalam J Health 5: 1-12.

28. Quina CR, Almazan JU, Tagarino JB, 2014. Knowledge, attitudes, and practices of leptospirosis in Catbalogan city, samar, Philippines. Am J Public Health Res 2: 91-98.

29. Arbiol J, Orencio P, Nomura H, Takahashi Y, Yabe M, 2016. Knowledge, attitude and practices towards leptospirosis among lakeshore communities of Calamba and Los Baños, Laguna, Philippines. Agriculture 6: 18

30. Likert RA, 1932. Technique for the measurement of attitudes. Arch Psychol 22: 1-55.

31. R core Team, 2016. R: A Language and Environment for Statistical Computing. Vienna, Austria: R Foundation for Statistical Computing. Available at: https://www.R-project.org/.

32. Koenraadt CJ, Tuiten W, Sithiprasasna R, Kijchalao U, Jones JW, Scott TW, 2006. Dengue knowledge and practices and their impact on Aedes aegypti populations in Kamphaeng Phet, Thailand. Am J Trop Med Hyg 74: 692-700.

33. Burnham KP, Anderson DR, 2007. Model Selection and Multimodel Inference: A Practical Information-Theoretic Approach. New York, NY: Springer.

34. Bozdogan $H, 1987$. Model selection and Akaike's information criterion (AIC): the general theory and its analytical extensions. Psychometrika 52: 345-370.

35. Rogala MB, 2017. Health promotion actions in mass-media for seniors in selected European countries. Epidemiol Biostat Public Health 14: 1-10.

36. Randolph KA, Whitaker $P$, Arellano A, 2012. The unique effects of environmental strategies in health promotion campaigns: a review. Eval Program Plann 35: 344-353.
37. Koizumi N, Muto M, Yamamoto S, Baba Y, Kudo M, Tamae Y, Soma H, 2008. Investigation of reservoir animals of Leptospira in the northern part of Miyazaki Prefecture. Jpn J Infect Dis 61: 465-468.

38. Lagadec E, Gomard $\mathrm{Y}$, Guernier V, Dietrich M, Pascalis H, Temmam S, Ramasindrazana B, Goodman SM, Tortosa P, Dellagi K, 2012. Pathogenic Leptospira spp. in bats, Madagascar and Union of the Comoros. Emerg Infect Dis 18: 1696-1698.

39. Andersen-Ranberg EU, Pipper C, Jensen PM, 2016. Global patterns of Leptospira prevalence in vertebrate reservoir hosts. $J$ Wildl Dis 52: 468-477.

40. Haake DA, Levett PN, 2015. Leptospirosis in humans. Curr Top Microbiol Immunol 387: 65-97.

41. Ricardo T, Bergero LC, Bulgarella EP, Previtali MA, 2018. Knowledge, attitudes and practices (KAP) regarding leptospirosis among residents of riverside settlements of Santa Fe, Argentina. PLoS Negl Trop Dis 12: e0006470.

42. Rosenstock IM, 1974. Historical origins of the health belief model. Health Educ Monogr 2: 328-335.

43. Ismail MH, 2008. The Role of Interpretive Signage in Enhancing Conservation Knowledge, Awareness and Behaviour Among Visitors at the Penang National Park, Masters dissertation, Universiti Putra Malaysia, Serdang, Malaysia.

44. Zahiruddin WM et al., 2018. Development and validation of a new knowledge, attitude, belief and practice questionnaire on leptospirosis in Malaysia. BMC Public Health 18: 331.

45. Kostenius C, Hallberg J, Lindqvist AK, 2018. Gamification of health education. Health Educ 118: 354-368.

46. Azhari NN, Abdul Manaf R, Ng SW, Shakeeb Arsalaan Bajunid SFB, Mohd Gobil AR, Saad WZ, Amin Nordin S, 2019. Gamification, a successful method to foster leptospirosis knowledge among university students: a pilot study. Int J Environ Res Public Health 16: 2108.

47. Thayaparan S, Robertson ID, Fairuz A, Suut L, Abdullah MT, 2013. Leptospirosis, an emerging zoonotic disease in Malaysia. Mal $\mathrm{J}$ Pathol 35: 123-132.

48. El-Jalii IM, 2000. Epidemiology and Diagnosis of Human Leptospirosis in Malaysia, Doctoral dissertation, Universiti Putra Malaysia, Serdang, Malaysia.

49. Tan WL, Soelar SA, Suan MAM, Hussin N, Cheah WK, Verasahib K, Goh PP, 2016. Leptospirosis incidence and mortality in Malaysia. Southeast Asian J Trop Med Public Health 47: 434-440. 